\title{
Factors affecting the dynamics of the honeybee (Apis mellifera) hybrid zone of South Africa
}

\author{
M Beekman ${ }^{1}, \mathrm{MH}$ Allsopp ${ }^{2}$, TC Wossler ${ }^{3}$ and BP Oldroyd ${ }^{1}$ \\ ${ }^{1}$ Behaviour and Genetics of Social Insects Lab, School of Biological Sciences A12, University of Sydney, Sydney, Australia; ${ }^{2}$ Honeybee \\ Research Section, ARC-Plant Protection Research Institute, Stellenbosch, South Africa and ${ }^{3}$ Department of Botany and Zoology, \\ DST-NRF Centre of Excellence for Invasion Biology, University of Stellenbosch, Matieland, South Africa
}

\begin{abstract}
Hybrid zones are found wherever two populations distinguishable on the basis of heritable characters overlap spatially and temporally and hybridization occurs. If hybrids have lower fitness than the parental types a tension zone may emerge, in which there is a barrier to gene flow between the two parental populations. Here we discuss a hybrid zone between two honeybee subspecies, Apis mellifera capensis and $A . m$. scutellata and argue that this zone is an example of a tension zone. This tension zone is particularly interesting because $A$. $m$. capensis can be a lethal social parasite of A. m. scutellata. However, despite its parasitic potential,
\end{abstract}

A. $m$. capensis appears to be unable to increase its natural range unassisted. We propose three interlinked mechanisms that could maintain the South African honeybee hybrid zone: (1) low fitness of intercrossed and genetically mixed colonies arising from inadequate regulation of worker reproduction; (2) higher reproductive success of $A$. $m$. scutellata via both high dispersal rates into the hybrid zone and increased competitiveness of males, countered by (3) the parasitic nature of $A$. $m$. capensis.

Heredity (2008) 100, 13-18; doi:10.1038/sj.hdy.6801058; published online 12 September 2007

Keywords: Apis mellifera capensis; A. m. scutellata; hybridization; reproductive division of labour; social parasitism; thelytoky

\section{Introduction}

Hybrid zones are 'narrow regions in which genetically distinct populations meet, mate and produce hybrids' (Barton and Hewitt, 1985). Hybrid zones usually arise after fragmentation of a panmictic population, which is later rejoined. Depending on the differences between the formerly isolated sub-populations, the resulting hybrid zone can either be a transient phase ultimately leading to the re-establishment of one interbreeding population, or the two sub-populations may remain separated. If the parental genotypes have become adapted to different ecological conditions, the frequency of parental genotypes may form a cline along an ecological gradient (Hewitt, 1988), or may form a 'mosaic' pattern across the landscape, reflecting different ecological zones (Harrison and Rand, 1989). Conversely, if the separating causes are endogenous (that is determined by genetic incompatibilities), a 'tension' zone may be formed between the two parental populations, which forms a barrier to gene flow between the two. Tension zones are maintained by a balance between dispersal of parentals into the zone and selection against hybrids within it (Barton and Hewitt, 1985).

Various mechanisms may reduce the fitness of hybrids relative to their parental types. These include regulatory

Correspondence: Dr M Beekman, Behaviour and Genetics of Social Insects Lab, School of Biological Sciences A12, University of Sydney, Macleay Building, Sydney, New South Wales 2006, Australia.

E-mail:mbeekman@bio.usyd.edu.au

Received 21 February 2007; revised 31 July 2007; accepted 3 August 2007; published online 12 September 2007 incompatibilities between transcription factors and the genes that they control (Noor, 2006), disruption of coadapted gene complexes (Barton, 2001), chromosomal incompatibilities between parental populations (FelClair et al., 1996) or behavioural mechanisms such as assortative mating, which prevent hybrids from finding mates or copulating with them (Moore and Price, 1993). When hybrid fitness is lower than the fitness of either parental type, gene flow is impeded across the tension zone (Barton and Hewitt, 1985). Where they occur, tension zones tend to be found in regions of low population density, where rates of dispersal of the parental genotypes into the zone are low (Hewitt, 1988).

Here we discuss a hybrid zone between two subspecies of honeybee in South Africa: the Cape honeybee, Apis mellifera capensis Escholtz 1821 (hereafter capensis), and the African honeybee, A. m. scutellata Lepeletier 1836 (hereafter scutellata). This hybrid zone is particularly interesting because capensis can be a lethal social parasite of scutellata. However, despite its parasitic potential, parasitism by capensis workers has not been observed outside the natural range of capensis without artificial movement by humans.

\section{Nature of the hybrid zone}

Based on mitochondrial and micorosatellite markers capensis and scutellata populations are indistinguishable (Franck et al., 2001) but are nevertheless characterized by significant differences in behavioural and morphological traits (see further). The two subspecies are separated by a hybrid zone with capensis confined to the southernmost 
part of the country and scutellata throughout the rest of South Africa and to countries to its north (Ruttner, 1988).

Although we cannot be certain how capensis and scutellata originally became separated, we do know that the Cape bee subsequently evolved some extraordinary and unique characteristics. Foremost among these is thelytokous parthenogenesis, in which unmated workers are able to lay eggs that develop into diploid females (Onions, 1914). This contrasts with all other honeybee species in which unmated workers produce haploid males via arrhentokous parthenogenesis.

The unique ability of capensis-workers to produce female offspring has resulted in calls for its conservation. Fears were expressed that hybridization between capensis and the much larger scutellata population might drive the only thelytokous honeybee race to extinction (Anderson, 1980). Contrary to this expectation, however, scutellata colonies introduced into the Cape area tend to die out when they are kept in proximity to capensis apiaries (Allsopp, 1993).

The cause of the disappearance of scutellata colonies when in the vicinity of capensis colonies is the ability of capensis workers to parasitize non-capensis colonies by entering them, activating their ovaries and producing diploid eggs that are reared by the host colony to produce yet more parasitic daughter workers (Allsopp, 1992). Because parasitizing capensis workers rarely, if ever, produce a new capensis queen an infestation with parasitic capensis workers ultimately leads to the death of the host colony. Yet, despite having the capacity to become a social parasite, capensis is unable to spread north of the Cape area unless assisted by beekeepers. Instead, a hybrid zone exists in which capensis and scutellata interbreed without causing a breakdown of the zone or loss of the distinct characteristics of each subspecies (Hepburn and Crewe, 1991).

Evidence for interbreeding within the hybrid zone comes from a study that showed that in queenless colonies within the zone workers produce both males (by arrhenotoky-scutellata type) and females (by thelytoky-capensis type) (Hepburn and Crewe, 1991), demonstrating that such colonies are the product of a cross between capensis- and scutellata-derived genotypes. The clinal gradient of sting pheromone components further shows that the two interbreed within the hybrid zone (Hepburn et al., 1994).

The bulk of the hybrid zone occurs within the semiarid areas of the Karoo ecotone, an area $100-200 \mathrm{~km}$ wide situated between latitudes $31 \mathrm{~S}$ and 33S, where densities of wild honeybee colonies are low (Ruttner, 1977). However, the coastal area east of the country likely provides a significant corridor for contact between capensis and scutellata populations (Ruttner, 1977). Even within the semi-arid areas of the Karoo there is significant contact between the two subspecies due to bee movements via beekeepers (Ruttner, 1977). Moreover, the contemporary Karoo is a fairly recent ecosystem (Tyson, 1987). Until 300 years ago the Karoo was an extensive grassland, almost certainly inhabited by honeybees (as evidenced by the large number of beerelated place names (Nienaber and Raper, 1983)) and suggesting that there was also significant contact between the two subspecies in historical times. This raises the question as to how capensis and scutellata remain separated.

\section{Reproductive biology of honeybees}

In order to understand how the two subspecies interact and what the likely effect is of interbreeding within the hybrid zone, we need to discuss reproductive biology of honeybees in some detail. We also need to discuss aspects of the biology of both capensis and scutellata with respect to their potential ability to increase their range, as well as behaviour that sets them apart from the other subspecies.

Honeybee colonies comprise a single mated queen and 10-50000 of her worker daughters. Because of haplo-diploidy the queen can choose the sex of her offspring. Eggs that are fertilized produce diploid female offspring (workers and queens), whereas (except in capensis workers) unfertilized eggs develop as haploid males.

In order to mate, a virgin queen flies to drone aggregations on 1-4 successive afternoons, mating with 6-10 males on each flight (Tarpy and Page, 2000). Large numbers of colonies contribute males to each aggregation. Where more than one subspecies co-occur, assortative mating may occur via spatial separation of drones of different subspecies within mating aggregations and temporal separation of mating flights (Koeniger et al., 1989). However, queens regularly mate with drones of different subspecies, resulting in colonies of mixed subspecies paternity.

New queens are produced prior to swarming. As soon as the virgin daughter queens are ready to emerge, the motherqueen and approximately half the workers leave the parental nest to establish a new colony. In the meantime, the first daughter queen to emerge will seek out her pupal or just-emerged sisters and kill them. There is therefore a fitness premium for being the first virgin to emerge.

Honeybee caste determination is primarily based on differential feeding of female larvae; thus queens are genetically identical to workers. Queen-destined larvae receive larval food that is richer in certain sugars and receive it in greater amounts than do worker-destined larvae (de Wilde and Beetsma, 1982). Hence, worker larvae can potentially manipulate adult nurse workers by soliciting more larval food and becoming more queenlike as a result (Allsopp et al., 2003).

A queen signals her presence to workers via pheromones. Workers respond to pheromones produced by the queen herself, and to those produced by her brood, in various ways, most notably by not producing their own offspring (reviewed in Barron et al. (2001)). This means that worker reproduction is normally absent in the presence of a queen and her brood. However, if the queen is lost and the colony fails to rear a replacement, workers activate their ovaries and lay eggs that produce fully viable offspring. During this period of worker reproduction there is reproductive competition among workers, and some subfamilies (worker daughters of a particular male) have higher reproductive success than others (Martin et al., 2004).

\section{Reproductive biology of capensis-predispositions to reproductive parasitism}

Not only is capensis the only honeybee in which the workers are able to produce diploid offspring, its' 
workers often show traits that are normally only found in queens. Capensis workers tend to have: (1) a large number of ovarioles (10-20 compared with 3-5 in other subspecies (Ruttner, 1988)); (2) an organ, the spermatheca, normally used by queens for the storage of sperm which is absent in workers of all other subspecies (Onions, 1914) and (3) in laying workers, a pheromonal bouquet that resembles that of queens (Wossler, 2002). In addition to laying workers producing queen-like pheromonal bouquets, a capensis queen, and presumably her brood as well (Allsopp et al., 2003), produce a much greater quantity of pheromone than any other honeybee subspecies (Crewe, 1988). Hereafter we refer to the characteristics unique to capensis workers (thelytoky, high number of ovarioles, presence of spermatheca and queen-like pheromonal bouquets) as the capensis complex.

As a consequence of thelytokous worker reproduction, reproductive competition among queenless capensis workers is expected to be even stronger than in honeybee subspecies in which workers can only produce males (Greeff, 1996). Because she can lay diploid eggs that are substantially clones of herself, a capensis worker has the potential to become the mother of the future queen of the colony; and in genetic terms she becomes the new queen herself. As might be expected, reproductive competition among queenless capensis worker subfamilies is intense. First, larvae of some subfamilies are apparently much more likely to be reared as queens than larvae of other subfamilies (Moritz et al., 2005). Second, workers of some subfamilies pheromonally prevent other subfamilies from activating their ovaries (Crewe and Velthuis, 1980), eventually dominating in egg laying and monopolizing the colony's reproductive output (Moritz et al., 1996).

\section{Capensis as a reproductive parasite}

Capensis workers in a colony headed by a capensis queen mated to capensis drones behave as any other honeybee worker (Allsopp and Hepburn, 1997). However, problems can arise when a capensis worker finds herself in a scutellata colony. Most likely capensis workers require higher levels of pheromones than are normally required to regulate reproductive division of labour (given that their queen and her brood elicit higher amounts, see above). As a result, the mixing of capensis with noncapensis genotypes within one colony results in a cascade of events caused by pheromonal imbalances between the two subspecies (see Neumann and Moritz (2002) for an overview).

Capensis infestations recently played havoc in northern South Africa. In 1992 around 400 capensis colonies were moved into the scutellata zone (Allsopp, 1993). As early as 1993 it was estimated that 50000 scutellata colonies had died due to the infestation (Greeff, 1997).

Microsatellite studies have shown that this infestation almost certainly arose from a single capensis worker that has multiplied automatically to produce a vast parasitizing population of workers of very similar genotype (Baudry et al., 2004). One is tempted to presume that this pseudo-clone has special characteristics that favour parasitism. However, records of other outbreaks suggest that the potential for social parasitism is not unique to this particular pseudo-clone, and that many capensis workers have the potential to form lineages capable of parasitizing scutellata colonies.

Reproductive biology of scutellata-a proven invader The reproductive biology of the scutellata-derived 'Africanized honeybee' (hereafter AHB) has been extensively studied in the American neotropics (for an overview and references see Schneider et al., 2004). AHB has been shown to have a strong reproductive advantage over European subspecies. Whether scutellata has the same reproductive advantage over capensis is unknown, but our assumption is that the reproductive biology of AHB is similar to that of scutellata in its native range.

AHB colonies show a greater emphasis on pollen than nectar collection, and this pollen is rapidly converted into brood. AHB colonies produce more brood per adult worker than other honeybee subspecies, resulting in high growth rates and increased swarm production. Likewise, drone production is high, resulting in a mating advantage of AHB males due to numerical superiority at drone aggregations. Moreover, AHB drones tend to drift into other colonies, thereby suppressing drone production by the host colony. Male migration from AHB colonies into European ones was almost certainly an important factor in the displacement of European subspecies in the Americas.

During queen rearing (prior to swarming or to replace the mother queen), AHB virgin queens may have a competitive advantage in colonies that have both $\mathrm{AHB}$ and non-AHB parentage. This advantage arises from $\mathrm{AHB}$ virgin queens developing faster than queens of other genotypes. Thus, if a colony has patrilines arising from both scutellata and non-scutellata males, it is more likely that a virgin from a scutellata patriline will inherit the colony because they tend to emerge first and kill their rivals.

\section{What happens in capensis scutellata hybrid colonies?}

The term 'hybrid' can have several different meanings in the context of a polyandrous insect colony, so we discuss this issue first. First a hybrid colony can arise if a queen mates with drones of a different subspecies, in which case her workers are $F_{1}$ hybrids. Hereafter we call such colonies $\mathrm{F}_{1}$ hybrids. Second, a queen could mate with drones of both her own subspecies and those of another subspecies, in which case there will be a mixture of $F_{1}$ and parental workers in the colony. We will call these 'mixed' colonies. Finally a colony might arise from intercrosses (crosses between hybrids or between hybrids and parentals) in which case there will be a variety of worker genotypes present. We refer to these colonies as intercrossed colonies.

We know that $F_{1}$ matings produce viable colonies without signs of reproductive parasitism by capensis workers (Crewe and Allsopp, 1994; Jordan et al., 2007). Most likely $F_{1}$ colonies contain sufficient numbers of capensis-derived genotypes to prevent the expression of worker reproduction due to differences in the pheromonal thresholds that regulate reproductive division of labour. However, based on previous work (Allsopp et al., 2003), we strongly suspect that as soon as colonies contain a mixture of capensis- and scutellata-derived 
subfamilies, as in intercrossed colonies, differences in the pheromonal thresholds lead to misinterpretation of intersubspecies signals. Most important in this regard are the pheromonal cues that regulate the feeding of larvae. If capensis and scutellata larvae are cross-fostered into colonies of the opposite subspecies, capensis larvae are fed more by scutellata nurse workers than when reared by their own sisters (Allsopp et al., 2003). Conversely, scutellata brood receive less food when fed by capensis nurse workers (Allsopp et al., 2003). Colonies from the hybrid zone (which are presumably intercrossed colonies) feed capensis larvae significantly more and scutellata larvae significantly less than they do larvae of their own genotype (Allsopp et al., 2003). Furthermore when larvae from intercrossed colonies of the hybrid zone are reared by capensis nurse workers, they are fed less compared with when they are reared by workers of their own genotype, whereas the opposite is true when the nurse workers are scutellata. It seems that capensis larvae 'ask' for more food than scutellata larvae, resulting in capensis larvae being fed more when nursed by scutellata workers. Similarly, scutellata larvae 'ask' for less food than capensis larvae, resulting in capensis nurse workers feeding scutellata larvae less then they would feed to capensislarvae. Larvae from colonies of the hybrid zone show an intermediate response. This means that larvae expressing capensis-like traits are likely to receive more food than either scutellata or hybrid larvae, whatever the average genotype of the colony. When worker larvae are fed an excessive amount of larval food, the resulting workers are more queen-like, showing decreased pupal development time, increased wet weight and size of spermatheca and reduced pollen combs on the basitarsus (Allsopp et al., 2003). The rearing of such queen-like workers is likely to come at a colony-level cost, for example when overfed individuals instead of performing worker tasks become reproductively active.

\section{A model for maintenance of the capensis-scutellata hybrid zone}

If we are correct and intercrossed colonies suffer from a breakdown of reproductive division of labour, these colonies will show a reduction in fitness relative to $F_{1}$ and parental colonies. We also predict that in the north of the zone, close to the scutellata parental population, there is selection towards a scutellata type. This selection primarily arises from the very high rates of production of swarms and drones by scutellata colonies (Rinderer et al., 1985). Presumably scutellata drones massively outnumber drones of any other genotype (capensis or hybrid) in the north of the hybrid zone. If queens, of any genotype, are inseminated by rare capensis males, these males are likely to have low reproductive success. First, scutellata spermatozoa may be more competitive than capensis spermatozoa, and will therefore be overrepresented in offspring (DeGrandi-Hoffman et al., 2003). Second, daughter virgin queens of scutellata males may develop faster and have superior fighting abilities compared with daughters of capensis males (DeGrandiHoffman et al., 1998). Thus daughters of scutellata males are more likely to inherit colonies after queen replacement or reproductive swarming, driving the northern hybrid population towards the parental scutellata type.
In the south of the hybrid zone, we hypothesize strong selection towards the capensis type due to the capacity of capensis workers to become parasites of non-capensis colonies, particularly intercrossed colonies. Hence, any colony that does not express the capensis phenotype will be vulnerable to reproductive parasitism by capensis workers originating from capensis colonies.

Moving towards the centre of the zone, colonies that show mixtures of scutellata and capensis-like traits are found (Hepburn and Crewe, 1991; Hepburn et al., 1994). We propose that these intercrossed and mixed colonies have low reproductive success when different workers in a colony differentially express capensis and scutellata traits. This can arise when queens mate with a mixture of capensis and scutellata drones, and in second and third generation intercrossed colonies. In this case the breakdown of reproductive division of labour arises from within the colony (contrary to parasitism coming from without), due to the minority capensis genotypes becoming reproductively active.

Critical to understanding the genetic architecture of intercrossed colonies is the mode of inheritance of the capensis-complex (thelytoky, high ovariole number, spermatheca and queen-like pheromonal bouquet). Many of the capensis-complex traits are controlled by a single locus (Lattorff et al., 2007), so some intercrossed workers will express the complete suite of capensis-complex traits, while other workers, not inheriting this allele will not. The presence of individuals that do and do not express the capensis-complex traits within an intercrossed or mixed colony will not have adverse consequences as long as the majority of the subfamilies within the colony are of the capensis phenotype (likely in the southern part of the hybrid zone). This is because there will be no pheromonal imbalances between capensis and noncapensis worker genotypes, and the colony will appear to be a capensis colony. However, when there are only a few subfamilies expressing capensis traits within an intercrossed or mixed colony (likely towards the centre of the hybrid zone), capensis workers will misinterpret pheromonal signals emitted from their half-sisters, the brood and possibly the queen (if the queen expresses the scutellata phenotype). These capensis workers are likely to perceive their colony as being queenless and become reproductively active, ultimately resulting in a dwindling colony and hence a severe reduction in reproductive success.

In addition to the locus that influences pheromone production, onset of reproduction and thelytoky pleiotropically (Lattorff et al., 2007), there is most likely a second locus that influences the amount of food that a worker larva is fed (Jordan et al., 2007). Individuals that receive more food are more likely to develop queenlike traits, that is, are more likely to become reproductively active, or to be reared as queens. The amount of food a larva receives depends both on the genotype of the larva as well as the genotype of the nurse worker. Hence, again, this will result in frequency-dependent expression of worker reproduction in intercrossed and mixed colonies. The presence of scutellata nurse workers and capensis brood within the same colony, will lead to capensis brood being over-fed by scutellata nurse workers, resulting in reproductively active capensis workers. 


\section{Conclusions}

In this review we have tried to identify possible mechanisms that maintain the capensis-scutellata hybrid zone in South Africa. We suggest that there is selection to parental capensis on the south margin of the zone caused by parasitism of any colony showing scutellata traits. In the north margin there is selection to scutellata caused by excessive production of scutellata males and swarms and a selective advantage of fast-developing queens. Within the hybrid zone intercrossed and mixed colonies suffer intra-colonial reproductive conflicts, which put them at a severe disadvantage relative to either parental type. We have argued that capensis and scutellata remain separated due to endogenous factors related to reproductive division of labour and that the hybrid zone is thus an example of a tension zone, maintained by a reduced fitness of intercrossed and mixed colonies.

The hypothesis that we propose assumes an essential role of frequency-dependent selection on reproductive division of labour. Such mechanism is not unique. For example frequency-dependent mechanisms maintain a hybrid zone of flickers where territory defence depends critically on the shaft colour of the males (Moore and Price, 1993). Birds that have the minority shaft colour are not able to obtain a territory as the majority of males are unimpressed by the colour of the minority males' shafts. Hence, selection favours the majority genotype when the two co-occur and individuals within the hybrid zone have reduced fitness compared with individuals in populations where only one shaft colour occurs. Frequency dependence also plays a role in the Australian frogs Litoria sp. and Geocrinia sp. where females are attracted to the males' advertisement calls (Littlejohn and Watson, 1985) and use call frequency to discriminate between males of their own species. However, because of clinal variation in call frequency, call frequencies of sympatric individuals overlap more than the frequencies of individuals outside this zone. As a result females within the hybrid zone are not able to discriminate between males of their own species and those of the sympatric species resulting in interspecific matings.

Honeybees have often served as a model species for investigating questions of general relevance. For example, after its introduction into Brazil in 1956, scutellata colonized much of the Americas in less than 50 years and therefore provided a unique opportunity to study the factors that determine the success of an invading subspecies (Schneider et al., 2004). Because of the amenability of honeybees to experimental manipulation, the capensis-scutellata hybrid zone provides a fascinating system for studying factors that maintain the separation of two social insect subspecies. Our tension zone hypothesis can be tested by constructing colonies comprising different proportions of capensis and scutellata patrilines and determining the colony's relative survival and reproductive success. We can also test some of the other assumptions that we have made, for example the higher reproductive success of scutellata in the north of the hybrid zone. Although we suspect that the capensisscutellata hybrid zone is maintained by endogenous factors only, the effect of ecological factors could potentially be studied by performing reciprocal transplant experiments (for example Bronson et al., 2003; Buggs and Pannell, 2007) provided it is possible to prevent experimental colonies from being parasitized by capensis. In fact an alternative hypothesis for the stability of the capensis-scutellata hybrid zone argues that it is maintained by ecological factors only (Hepburn and Crewe, 1991). Hence, further research will enable us to disentangle the exact biological mechanisms that keep the honeybees of South Africa apart.

\section{Acknowledgements}

We thank Bill Hughes, Christian Peeters, Graham Thompson and other members of the Social Insects Lab for discussions and constructive comments. We also thank the anonymous referees for their comments. Johan Calis is thanked for sharing his ideas and providing us with unpublished data at a very early stage of this manuscript. $\mathrm{MB}$ and $\mathrm{BPO}$ are supported by the Australian Research Council. TCW is supported by the National Research Foundation. Additional financial support was obtained from a University of Sydney Senior International Research Fellowship to MB. Because the number of references was limited to 40 , we apologize to all our colleagues who we should have cited but could not.

\section{References}

Allsopp MH (1992). The Capensis calamity. S Afr Bee J 64: 52-57. Allsopp MH (1993). Summarized overview of the Capensis problem. S Afr Bee J 65: 127-136.

Allsopp MH, Calis JNM, Boot WJ (2003). Differential feeding of worker larvae affects caste characters in the Cape honey bee, Apis mellifera capensis. Behav Ecol Sociobiol 54: 555-561.

Allsopp MH, Hepburn HR (1997). Swarming, supersedure and the mating system of a natural population of honey bees (Apis mellifera capensis). I Apic Res 36: 41-48.

Anderson RH (1980). Cape honey-bee sanctuaries. S Afr Bee J 52: 5-9.

Barron AB, Oldroyd BP, Ratnieks FLW (2001). Worker reproduction in honey-bees (Apis) and the anarchistic syndrome: a review. Behav Ecol Sociobiol 50: 199-208.

Barton NH (2001). The role of hybridization in evolution. Mol Ecol 10: 551-568.

Barton NH, Hewitt GM (1985). Analysis of hybrid zones. Ann Rev Ecol Syst 16: 113-148.

Baudry E, Kryger P, Allsopp MH, Koeniger N, Vautrin D, Mougel F et al. (2004). Whole-genome scan in thelytokouslaying workers of the Cape honeybee (Apis mellifera capensis): central fusion, reduced recombination rates and centromere mapping using half-tetrad analysis. Genetics 167: 243-252.

Bronson CL, Grubb TC, Braun MJ (2003). A test of the endogenous and exogenous hypotheses for the maintenance of a narrow avian hybrid zone. Evolution 57: 630-637.

Buggs RJA, Pannell JR (2007). Ecological differentiation and diploid superiority across a moving ploidy contact zone. Evolution 61: 125-140.

Crewe RM (1988). Natural history of honey-bee mandibular gland secretions: development of analytical techniques and the emergence of complexity. In: Needham GR, Page RE, Delfinado-Baker M, Bowman C (eds). Africanized Honey Bees and Bee Mites. Ellis Horwood: Chichester. pp 149-158.

Crewe RM, Allsopp MH (1994). Sex and the single queen: recent experiments with capensis and scutellata queens. S Afr Bee J 66: 58-62.

Crewe RM, Velthuis HHW (1980). False queens: a consequence of mandibular gland signals in worker honeybees. Naturwissenschaften 67: 467-469.

DeGrandi-Hoffman G, Tarpy DR, Schneider SS (2003). Patriline composition of worker populations in honeybee (Apis 
mellifera) colonies headed by queens inseminated with semen from African and European drones. Apidologie 34: 111-120.

DeGrandi-Hoffman G, Watkins JC, Collins AM, Loper GM, Martin JH, Arais M et al. (1998). Queen developmental time as a factor in the Africanization of European honey bee (Hymenoptera: Apidae) populations. Ann Entomol Soc Am 91: 52-58.

de Wilde J, Beetsma J (1982). The physiology of caste development in social insects. Advances in Insect Physiology 16: 167-246.

FelClair F, Lenormand T, Catalan J, Grobert J, Orth A, Boursot P et al. (1996). Genomic incompatibilities in the hybrid zone between house mice in Denmark: evidence from steep and non-coincident chromosomal clines for Robertsonian fusions. Genet Res 67: 123-134.

Franck P, Garnery L, Loiseau A, Oldroyd BP, Hepburn HR, Solignac M et al. (2001). Genetic diversity of the honeybee in Africa: microsatellite and mitochondrial data. Heredity 86: 420-430.

Greeff JM (1996). Effects of thelytokous worker reproduction on kin-selection and conflict in the Cape honeybee, Apis mellifera capensis. Phil Trans $R$ Soc Lond B 351: 617-625.

Greeff JM (1997). The Cape honeybee and her way north: an evolutionary perspective. S Afr J Sci 93: 306-308.

Harrison RG, Rand DM (1989). Mosaic hybrid zones and the nature of species boundaries. In: Otte D, Endler JA (eds). Speciation and Its Consequences. Sinauer: Sunderland, MA pp 111-133.

Hepburn HR, Crewe RM (1991). Portrait of the Cape honeybee, Apis mellifera capensis. Apidologie 22: 567-580.

Hepburn HR, Jones GE, Kirby R (1994). Introgression between Apis mellifera capensis Escholtz and Apis mellifera scutellata Lepeletier: the sting pheromones. Apidologie 25: 557-565.

Hewitt GM (1988). Hybrid zones-natural laboratories for evolutionary studies. Trend Ecol Evol 3: 158-167.

Jordan LA, Allsopp MH, Beekman M, Wossler TC, Oldroyd BP (2007). Inheritance of traits associated with reproductive potential in Apis mellifera capensis and A. m. scutellata workers. J Hered (submitted).

Koeniger G, Koeniger N, Pechhacker H, Ruttner F, Berg S (1989). Assortative mating in a mixed population of European honeybees, Apis mellifera ligustica and Apis mellifera carnica. Insectes Soc 36: 129-138.

Lattorff HMG, Moritz RFA, Crewe RM, Solignac M (2007). Control of reproductive dominance by the thelytoky gene in honeybees. Biol Lett 3: 292-295.
Littlejohn MJ, Watson GF (1985). Hybrid zones and homogamy in Australian frogs. Ann Rev Ecol Syst 16: 85-112.

Martin CG, Oldroyd BP, Beekman M (2004). Differential reproductive success among subfamilies in queenless honeybee (Apis mellifera L.) colonies. Behav Ecol Sociobiol 56: $42-49$.

Moore WS, Price JT (1993). Nature of selection in the northern flicker hybrid zone and its implications for speciation theory. In: Harrison RG (ed). Hybrid Zones and The Evolutionary Process. Oxford University Press: Oxford. pp 196-225.

Moritz RFA, Kryger P, Allsopp MH (1996). Competition for royalty in bees. Nature 384: 31 .

Moritz RFA, Lattorff HMG, Neumann P, Kraus FB, Radloff SE, Hepburn HR (2005). Rare royal families in honeybees, Apis mellifera. Naturwissenschaften 92: 488-491.

Neumann P, Moritz RFA (2002). The Cape honeybee phenomenon: the sympatric evolution of a social parasite in real time? Behav Ecol Sociobiol 52: 271-281.

Nienaber GS, Raper PE (1983). Hottentot (Khoekhoen) Place Names. Southern African Place Names: 1. Butterworth Publishers: Durban.

Noor MAF (2006). Speciation genetics: evolving approaches. Nat Rev Genet 7: 851-861.

Onions GW (1914). South African 'fertile worker bees'. Agric J Univ S Afr 7: 44-46.

Rinderer TE, Hellmich RL, Danka RG, Collins AM (1985). Male reproductive parasitism: a factor in the Africanization of European honeybee populations. Science 228: 1119-1121.

Ruttner F (1977). The problem of the Cape bee (Apis mellifera capensis Escholtz): parthenogenesis-size of populationevolution. Apidologie 8: 281-294.

Ruttner F (1988). Biogeography and Taxonomy of Honey Bees. Springer-Verlag: Berlin.

Schneider SS, Degrandi-Hoffman G, Smith DR (2004). The African honey bee: factors contributing to a successful biological invasion. Annu Rev Entomol 49: 351-376.

Tarpy DR, Page RE (2000). No behavioral control over mating frequency in queen honey bees (Apis mellifera L.): implications for the evolution of extreme polyandry. Am Nat 155: $820-827$.

Tyson PD (1987). Climatic Change and Variability in Southern Africa. Oxford University Press: Cape Town.

Wossler TC (2002). Pheromone mimicry by Apis mellifera capensis social parasites leads to reproductive anarchy in host Apis mellifera scutellata colonies. Apidologie 33: 139-163. 